NASA Technical Memorandum 105398

\title{
Ion Beam Treatment of Potential Space Materials at the NASA Lewis Research Center
}

Michael Kussmaul

Sverdrup Technology, Inc.

Lewis Research Center Group

Brook Park, Ohio

Michael J. Mirtich and Arthur Curren

National Aeronautics and Space Administration

Lewis Research Center

Cleveland, Ohio

Prepared for the

Surface Modification of Metals by Ion Beams sponsored by the Naval Research Laboratory

Washington, D.C., July 15-19, 1991

\section{N/Sก}




\title{
ION BEAM TREATMENT OF POTENTIAL SPACE MATERIALS
}

\section{AT THE NASA LEWIS RESEARCH CENTER}

\author{
Michael Kussmaul \\ Sverdrup Technology, Inc. \\ Lewis Research Center Group \\ Brook Park, Ohio 44142 \\ Michael J. Mirtich and Arthur Curren \\ National Aeronautics and Space Administration \\ Lewis Research Center \\ Cleveland, Ohio 44135
}

\begin{abstract}
SUMMARY
Ion source systems, in different configurations, have been used to generate unique surface morphologies for several NASA space applications. The discharge chamber of a $30 \mathrm{~cm}$ ion source was successfully used to texture potential space radiator materials for the purpose of obtaining values of thermal emittance greater than 0.85 at 700 and $900 \mathrm{~K}$. High absorptance surfaces were obtained using ion beam seed-texturing, for space radiator materials that were flown on the Long Duration Exposure Facility (LDEF) for 5.8 years in space. An ion source discharge chamber was also used to develop electrode surfaces with suppressed secondary electron emission characteristics for use in collectors in microwave amplifier traveling wave tubes. This was accomplished by sputtering textured carbon onto copper as well as texturing copper using tantalum and molybdenum as sacrificial texture-inducing seeding materials. In a third configuration, a dual ion beam system was used to generate high transmittance diamondlike carbon (DLC) films.
\end{abstract}

\section{INTRODUCTION}

Ion sources can be uniquely configured to generate surface morphologies or deposit thin films used in subsystems that are enabling technologies for space power and communication systems. This paper describes three such technologies that were developed with the use of an ion source. Space radiators for the proposed Space Station Freedom will be required to dissipate large amounts of waste heat produced by power generation. To minimize radiator size, due to space shuttle size and weight constraints, candidate radiator surface materials must have an emittance of 0.85 or greater. Space radiators in low Earth orbit (LEO) must also survive chemical attack in an atomic oxygen environment while maintaining the required emittance. Most radiator materials do not meet this requirement. It is, however, possible to increase thermal emittance through the use of either a coating (ref. 1), or increasing surface roughness (ref. 2). Coatings tend to have intrinsic stress (ref. 3) and can spall when thermally cycled or raised to elevated temperature levels (ref. 4). These phenomena, however, do not occur for surfaces that have been ion beam textured. Ion beam texturing increases the surface area of the emitting surface and thus changes its optical properties (refs. 2 and 5 to 10). Thus, enhanced emittance can be obtained without altering the surface chemistry and maintaining its integrity. Various potential space radiator materials were treated in an ion source discharge chamber with seed-texturing to alter their surface morphologies and hence improve their emittance. These textured materials were then flown on LDEF to test their ability to survive shuttle launch and the space environment. The optical properties and surface morphologies of these samples were examined both before and after their LDEF flight. 
In another application of surface modification by ion bombardment, candidate materials for the electrodes of multistage depressed collectors (MDC's) for microwave amplifier traveling wave tubes (TWT's) were treated to suppress secondary electron emission characteristics. The function of the MDC is to recover the maximum kinetic energy from the spent electron beam after it has passed through the radio frequency interaction section of the TWT. Among the significant factors in maximizing MDC efficiency is the use of electrode materials having low secondary electron emission characteristics (ref. 11) so that the electrons are not excessively reflected or reemitted from the surfaces. Reducing the secondary electron emission properties of MDC electrodes has been shown experimentally to significantly increase the efficiency of the MDC, as well as the overall TWT efficiency (ref. 12). This is of particular importance in tubes intended for space communications applications. While oxygen-free, high-conductivity (OFHC) copper has been the material most commonly used for MDC electrodes, it exhibits relatively high secondary electron emission if its surface is not treated for emission control. Treatments to effectively suppress the secondary electron emission of copper may be particularly attractive to the several TWT manufacturers using copper electrodes, since it can increase MDC efficiency without significantly changing basic design and fabrication procedures. Procedures used at NASA Lewis Research Center to produce several treated copper surfaces are described in this study, along with scanning electron photomicrographs of those surfaces and resulting experimentally-measured secondary electron emission characteristics.

Diamondlike carbon films have generated a great amount of interest as a result of the unique properties of this material and also because of the low temperatures at which these films can be deposited. The durable, smooth, adherent films are nearly transparent and impervious to reagents which dissolve graphitic and polymeric carbon structures. These amorphous films have many desirable characteristics, including extreme hardness, high transparency (both at visible and infrared wavelengths), high electrical resistivity, and low coefficient of friction and chemical inertness. At NASA Lewis, single and dual beam ion source systems are used to generate amorphous DLC films, which have been evaluated for a variety of applications including protective coatings on transmitting materials, power electronics, and corrosion-resistant barriers.

\section{ION BEAM TEXTURED SPACE RADIATOR MATERIALS}

\section{Apparatus and Procedure}

The schematic of the apparatus used to ion beam texture space radiator materials is shown in figure 1(a). Presented herein are two materials, (copper and titanium 16 percent vanadium and 2.5 percent aluminum $(\mathrm{Ti}(16,2.5))$ that were ion beam textured to increase emittance. Each material was exposed in the discharge chamber for various durations of time. Argon gas was fed into the discharge chamber at a flow rate of $80 \mathrm{scc} / \mathrm{min}$, ionized, and accelerated by the $-1500 \mathrm{~V}$ potential maintained between the sample and the ion source. During testing of various candidate radiator materials, the sample temperature, surface current density, and exposure time were varied to achieve the highest possible emittance. The sample was surrounded by a tantalum target, shown in figure 1(b), which was secured $0.79 \mathrm{~cm}$ above the holder and sloped outward at a $45^{\circ}$. angle. This tantalum target was used as a seed material to initiate and sustain the texturing process. Incoming ions sputtered the target $\mathrm{Ta}$ seed atoms on to the surface of the substrate where they nucleate into sites which act to shield the substrate from sputter etching. The resulting surface morphology was dependent upon the ratio of target to substrate sputter yields, ion energy, ion current density and also the substrate temperature. During most of the texturing procedure this skirt was at the same potential as the holder $(-1500 \mathrm{~V})$. However, during the final $10 \mathrm{sec}$ of texturing this potential was removed to facilitate ion beam cleaning to remove the unwanted seed material from the surface. 
High values of emittance are desired at 700 and $900 \mathrm{~K}$, thus low values of reflectance are needed in the wavelength region corresponding to 4 and $3 \mu \mathrm{m}$ respectively. Emittance values of the textured materials were measured in the infrared region ( 2 to $15 \mu \mathrm{m})$ using a hohlraum reflectometer. From spectral reflectance data obtained in the hohlraum, values of total emittance were obtained by normalizing to 700 and $900 \mathrm{~K}$ blackbodies.

The calculation for total emittance is:

$$
\varepsilon_{T}=1-\frac{\int \rho(\lambda) \phi(\lambda) d \lambda}{\int \phi(\lambda) d \lambda}=1-\frac{\sum_{i=0}^{27} \rho_{i}(\lambda) \phi_{i}(\lambda)\left(\Delta \lambda_{i}\right)}{\sum_{i=1}^{27} \phi_{i}(\lambda)\left(\Delta \lambda_{i}\right)}
$$

where $\rho_{i}(\lambda)$ is the spectral reflectance at $i=1,2.5,3, \ldots, 15 \mu \mathrm{m} . \phi_{i}(\lambda)$ is the spectral irradiance from 700 or $900 \mathrm{~K}$ blackbody, and $\left(\Delta \lambda_{i}\right)$ is $0.5 \mu \mathrm{m}$.

In 1984 the LDEF experiment was launched to passively measure the effects of prolonged exposure to the LEO environment on various space power system materials. Table I shows the optical properties of ion beam textured samples which were flown on the LDEF experiment from 1984 until 1989. This table shows that for these samples flown there were no significant changes in their optical properties, with the exception of sputter-textured copper, which increased in thermal emittance from 0.50 to 0.69 , probably due to oxidation.

Shown in figure 2 is the spectral emittance between 1.5 and $15.0 \mu \mathrm{m}$ for titanium $(16,2.5)$, textured at $1120 \mathrm{~K}$ for times varying from $15 \mathrm{~min}$ to $2 \mathrm{hr}$. Not enough structures were formed after $15 \mathrm{~min}$ to make a significant difference in the spectral emittance at any wavelength. After $2 \mathrm{hr}$ of texturing a fully developed (i.e., no untextured areas remain) surface morphology was produced, yielding emittances above 0.8 in the IR region. Continued texturing of titanium at these conditions produced no further changes in the values of emittance. Total emittance values for titanium at 700 and $900 \mathrm{~K}$ were 0.75 and 0.80 , respectively. It should be noted that diffuse reflectance measurements made on the samples with fully developed morphologies showed that the measured reflectances were totally diffuse. Figure 3 shows the spectral emittance of the $\mathrm{Cu}$ sample. The values of emittance for $\mathrm{Cu}$ were the highest obtained in this study, 0.978 at $700 \mathrm{~K}(4 \mu \mathrm{m})$ and 0.983 at $900 \mathrm{~K}(3 \mu \mathrm{m})$.

\title{
ION BEAM MODIFIED SURFACES FOR LOW SECONDARY ELECTRON EMISSION
}

\author{
Apparatus and Procedure
}

The ion-texturing facility used to modify the surface of copper to reduce secondary electron emission properties was the same as that used to texture surfaces for space radiators. For the purposes of this study, small copper disk samples $(2.10 \mathrm{~cm}$ diam. $\times 0.152 \mathrm{~cm}$ thick) were positioned in the instrumented receptacle shown in the schematic (fig. 1(a)) and were subjected to argon ion bombardment in a low-pressure (about $4 \times 10^{-5}$ torr) environment. Samples were cleaned before texturing by successively washing them in acetone, ethyl alcohol, and distilled water; then the samples were airdried. Variables in the texturing procedure included accelerating potential difference between the 
cathode and sample, argon flow rate, sample surface current density, and duration of ion bombardment. Referring to figure 1, the target of carbon or metal seeding material was mounted above, and surrounded the copper sample, or substrate, and sloped inward toward the substrate at a $45^{\circ}$ angle. The target diameter and spacing above the substrate (to which it was electrically connected) was dependent on the target material, as well as the substrate diameter and configuration, and was generally determined by some experimentation. In the case of the application of carbon to the copper surface, under the proper conditions, the carbon arriving at the substrate spontaneously forms the emission-suppressing highly-textured morphology (refs. 13 and 14). In the case of tantalum or molybdenum targets to texture copper substrates, however, the higher melting-point materials participated only as sacrificial texture-inducing masking or "seed," and remained on the textured surface only in relatively small amounts (refs. 15 and 16).

\section{Secondary Electron Emission Evaluation}

The surfaces studied in this investigation were evaluated for both true secondary electron emission (electrons emitted at low energies as a result of primary electron inelastic collisions and reflected primary yield characteristics (electrons reflected at near primary beam energy level after undergoing inelastic collisions). The suppression of both of these emissions is important to provide for maximum collector efficiency. Briefly, the textured copper samples were attached to a micromanipulatormounted support fixture and installed in an ultra-high-vacuum bell jar equipped with a scanning Auger spectrometer (CMA) having an integral electron gun. The samples were degassed with external bell jar and fixture heaters, after which their emission characteristics were evaluated at 11 electron beam energies ranging from 200 to $2000 \mathrm{eV}$. The ratio, $\delta$, of true secondary electrons emitted relative to those impinging was determined by taking the difference between the sample current to ground with the sample biased $(90 \mathrm{Vdc}$ ) and unbiased, and dividing by the current to ground while biased. The reflected primary electron yield index, $\pi$, was evaluated by comparing the elastic peak at each electron beam energy level as determined by the CMA, with the corresponding well-known elastic peak for a sooted control surface which was located on part of the sample surface. These procedures are described in detail in reference 15.

\section{Experimental Results}

Scanning Electron Microscope photomicrographs of textured surfaces studied in this investigation are presented in figures 4 to 6 . A typical mature textured carbon surface on a copper substrate is shown in figure 4 as produced by the procedures described in references 13 and 14. The surface is characterized by a densely-packed, uniform array of relatively sharp spires which display average heights and spacings of about 6 to $12 \mu \mathrm{m}$ and 3 to $6 \mu \mathrm{m}$, respectively. A mature textured copper surface produced using tantalum as the texture-inducing masking material (ref. 15) is displayed in figure 5. Here again the surface is a dense array of uniform projections from the substrate, but the peaks are relatively blunt with average heights and spacings of about 10 and $5 \mu \mathrm{m}$, respectively. Figure 6 presents a mature textured copper surface produced as described in reference 16 with the use of molybdenum as the masking, or target, material. This surface, while similar in morphology to that of figure 5 , has average heights and spacings of about 5 and $3 \mu \mathrm{m}$, respectively. These textured surfaces are here described as "mature," by which is meant that they represent the maximum feature maturity for the texturing conditions imposed: shorter processing periods produce less feature uniformity and smaller physical size relative to that shown in the figures, while longer processing periods do not significantly further improve either uniformity or produce larger size. Of course, the 
imposition of a set of texturing variables significantly different from those indicated in the captions of figures 4 to 6 will result in different heights, spacings, and uniformity.

\title{
Secondary Electron Emission Characteristics
}

The true secondary electron emission and reflected primary electron yield index of the textured surfaces which have been described are presented in figure 7. To illustrate the suppression of these characteristics for the treated surfaces relative to those of untreated copper, each figure also includes the corresponding characteristic curve for copper, taken from reference 13. In each figure, all of the textured surfaces demonstrate sharply lower emission or yield index than that for untreated copper. While none of the textured surfaces described here are necessarily "optimized" for secondary electron emission suppression, the preliminary improvement would result in significant enhancement of MDC's for TWT's efficiency. Furthermore, each of the treated surfaces is compatible with the fabrication and operation conditions experienced by these devices.

\section{DIAMONDLIKE CARBON (DLC) FILMS}

\author{
Apparatus and Procedure
}

DLC films were deposited using a single ion source or the dual ion beam source configuration shown in figure 8. Either a $30-\mathrm{cm}$ hollow cathode ion thruster with its extraction grids masked down to $15 \mathrm{~cm}$, or a $15-\mathrm{cm}$ cathode filament ion source with carbon grids was used as the direct DLC deposition source. The 30-cm ion source used either argon or xenon gases in a hollow cathode located in the main discharge chamber, as well as in a neutralizer (ref. 17). Once a discharge was established, methane gas was introduced into the chamber. For all DLC depositions performed in this manner the molar ratio of $\mathrm{CH}_{4}$ to Argon was 0.28 . A $15-\mathrm{cm}$ cathode filament source was also used to obtain a discharge with pure $\mathrm{CH}_{4}$. For these experiments, the total beam energy was the sum of the discharge and screen grid voltages, and was maintained about $100 \mathrm{~V}$. The current densities for these depositions was generally about $1 \mathrm{~mA} / \mathrm{cm}^{2}$ at a distance of $2.5 \mathrm{~cm}$ axially downstream of the grids (ref. 18). Under these conditions films were deposited at a rate of $71 \AA / \mathrm{min}$ on $\mathrm{Si}$ and $\mathrm{SiO}_{2}$ to thicknesses of $1.5 \mu \mathrm{m}$.

During dual-beam depositions an 8-cm cathode filament ion source, with its extraction grids masked to $4 \mathrm{~cm}$, was used to direct a beam of either argon, xenon or hydrogen ions at the substrate. The beams were approximately monoenergetic, however no mass selection was attempted to determine species.

\section{DLC EXPERIMENTAL RESULTS}

It is the goal of a joint effort (Space Act Agreement by NASA Lewis and Diamonex, Inc.) to obtain $1000 \AA$-thick DLC films with a transmittance of 85 percent at a wavelength of $5000 \AA$ (the peak of the visible spectrum) for DLC use as protective coatings for plastic ophthalmic lenses. Shown in figure 9 is the progress of ongoing research at NASA Lewis to use the dual ion beam system to decrease the absorptance of DLC films at $5000 \AA$, thereby improving their transmittance. As can be seen from this figure, to date the highest transmittances have been obtained when pure methane is run in the direct deposition ion source and a low energy hydrogen beam is maintained with the second source. The role of energetic hydrogen in improving transmittance of the DLC film is still under investigation. 
Listed in table II are values of H/C ratio, optical band gap, index of refraction, absorption coefficient and solar transmittance for DLC films made using both the single and dual beam systems. Some properties were enhanced by using a dual beam system. The solar transmittance and index of refraction are higher, and the absorption coefficient is lower when compared to the single ion source films. The remaining properties listed in table II were similar regardless of their method of deposition.

The adhesion of the films on quartz was measured following the procedure used by Mirtich (ref. 19). The adherence of the films generated by either the single and dual beam methods was greater than the maximum measurable adherence of the Sebastian Adherence Tester used in the measurement $\left(\sim 5.5 \times 10^{7} \mathrm{~N} / \mathrm{m}^{2}\right.$ or $\left.8000 \mathrm{psi}\right)$. The adherence was often found to be greater than the cohesion of the substrate, causing portions of the quartz to give way leaving the DLC film intact.

Angus et al. (ref. 20) measured the diffusion coefficient of Argon trapped at the DLC film/ substrate interface to be less than $10^{-18} \mathrm{~cm}^{2} / \mathrm{sec}$. This value is 10 orders of magnitude lower than argon diffusion in conventional hydrocarbons or polymers. Some films have been stored for up to 10 years with no obvious signs of deterioration. Figure 10 shows a plot of the coefficient of friction for a diamondlike carbon film sliding on steel as a function of relative humidity. As seen in the figure, for less than 1 percent the coefficient of friction is very low. This characteristic would indicate a potential use as a wear resistant surface in inert or vacuum environments.

Scratch tests were performed on DLC films deposited on quartz by rubbing $\mathrm{SiO}_{2}$ particles $(\sim 80 \mu \mathrm{m})$ across the surface. An abrasion test was also performed on these specimens by tumbling these samples in an environment $(\sim 80 \mu \mathrm{m})$ made up of rubber erasers and $\mathrm{SiO}_{2}$ particles. Results of these tests show that the DLC film protected the quartz from the abrasive effects of the $\mathrm{SiO}_{2}$ particles.

\section{CONCLUDING REMARKS}

Discharge chamber texturing can be used to develop morphologies in copper and $\operatorname{Ti}(16,2.5)$. Each material developed a unique reproducible morphology for the discharge chamber conditions explored in this paper. These microstructures resulted in extremely high values of thermal emittance $(0.978$ and 0.983$)$ for copper at 700 and $900 \mathrm{~K}$, respectively and 0.87 for stainless steel type 304 stainless steel, exceeding the 0.85 needed for SP 100 radiators. Thus, a discharge chamber of an ion source can be used to change a material's surface morphology to obtain values of thermal emittance higher than those of the pristine materials. The LDEF experiment showed that these sputter-deposited surface morphologies could survive the shuttle launch, the Low Earth Orbit environment for 5.8 years, and retrieval without optical performance degradation.

Processes for producing uniform highly-textured surfaces on oxygen-free, high-conductivity copper by means of appropriate ion-bombardment procedures have been developed at NASA Lewis. These surfaces demonstrate secondary electron emission characteristics which are sharply lower than those of untreated copper and therefore can be used as efficiency-enhancing electrodes in the multistage depressed collectors for traveling wave tubes. Continuing work on this program at NASA Lewis is directed at the optimization of these surfaces for emission suppression and the application of this technology to TWT's for space communication as well as aircraft and terrestrial applications.

A major advantage of DLC films is that they are smooth and adherent and can be deposited on substrates at room temperature. These features allow DLC films to readily be used in many applications where properties such as hardness, scratch resistance, hermeticity, and transparency are important. 


\section{REFERENCES}

1. Jurisson, J.; Peterson, R.E.; and Mar, H.Y.B.: Principles and Applications of Selective Solar Coatings. J. Vac. Sci. Technol., vol. 12, no. 5, 1975, pp. 1010-1015.

2. Hudson, W.R.; Weigand, A.J.; and Mirtich, M.J.: Optical Properties of Ion Beam Textured Metals-Using Copper, Silicon, Aluminum, Titanium, and Stainless Steel. NASA TM X-73598, 1977.

3. Kane, S.M.; and Ahn, K.Y.: Characteristics of Ion-Beam-Sputtered Thin Films. J. Vac. Sci. Technol., vol. 16, no. 2, 1979, pp. 171-174.

4. Mirtich, M.J.; Nieh, C.Y.; and Wallace, J.F.: Sputtered Protective Coatings for Die-Casting Dies. Thin Solid Films, vol. 84, no. 3, 1981, pp. 295-302.

5. Rossnagel, S.M.; and Robinson, R.S.: Optical Properties of Ion-Beam Microtextured Surfaces. J. Vac. Sci. Technol., vol. 20, no. 2, 1982, pp. 336-337.

6. Banks, B.A.: Topography: Texturing Effects. Handbook of Ion Beam Processing Technology, J.J. Cuomo and S.M. Rossnagel, eds., Noyes Publ., Park Ridge, NJ, 1989, Ch. 17.

7. Mirtich, M.J.; and Kussmaul, M.T.: Enhanced Thermal Emittance of Space Radiators by IonDischarge Chamber Texturing. NASA TM-100137, 1987.

8. Rutledge, S.K.; Hotes, D.; and Paulsen, P.E.: The Effect of Atomic Oxygen on the Thermal Emittance of High Temperature Radiator Surfaces. NASA TM-103224, 1989.

9. Mirtich, M.J., et al.: The Emittance of Space Radiator Materials Measured at Elevated Temperatures. NASA TM-101948, 1988.

10. Banks, B.A.; Rutledge, S.K.; and Hotes, D.: High Emittance Surfaces for High Temperature Space Radiator Applications. Optical Surfaces Resistant to Severe Environments; Proceedings of the Meeting, San Diego, CA, July 11-12, 1990, S. Musikant, ed., SPIE Proceedings, Vol. 1330, SPIE, 1990, pp. 66-70.

11. Kosmahl, H.G.; and Ramins, P.: Small Size 81-Percent to 83.5-Percent Efficient 2-Stage and 4-Stage Depressed Collectors for Octave-Bandwidth High-Performance Twits. IEEE Trans. Electron Devices, vol. 24, no. 1, Jan. 1977, pp. 36-44.

12. Curren, A.N.: Carbon and Carbon-Coated Electrodes for Multistage Depressed Collectors for Electron Beam Devices-A Technology Review. IEEE Trans. Electron Devices, vol. 33, no. 11, Nov. 1986, pp. 1902-1914.

13. Curren, A.N.; and Jensen, K.A.: Textured Carbon on Copper: A Novel Surface with Extremely Low Secondary Electron Emission Characteristics. NASA TP-2543, 1985.

14. Curren, A.N.; Jensen, K.A.; and Roman, R.F.: Textured Carbon Surfaces on Copper by Sputtering. U.S. Patent No. 4,607-193, Aug. 1986. 
15. Curren, A.N.; and Jensen, K.A.: Secondary Electron Emission Characteristics on Ion-Textured Copper and High-Purity Isotropic Graphite Surfaces. NASA TP-2342, 1984.

16. Curren, A.N.; and Jensen, K.A.: Secondary Electron Emission Characteristics of MolybdenumMasked, Ion-Textured OFHC Copper. NASA TP-2967, 1990.

17. Sovey, J.S.: A 30-cm Diameter Argon Ion Source-For Ion Thrusters and Sputtering. AIAA Paper 76-1017, 1976.

18. Mirtich, M.J.: Ion Beam Deposited Protective Films. AIAA Paper 81-0672, 1981.

19. Mirtich, M.J.: Adherence of Ion-Beam Sputter Deposited Metal Films on H-13 Steel. J. Vac. Sci. Technol., vol. 18, no. 2, Mar. 1981, pp. 186-189.

20. Angus, J.C., et al.: Ion Beam Deposition of Amorphous Carbon Films with Diamondlike Properties. Metastable Materials Formation by Ion Implantation; Proceedings of the Materials Research Society Annual Meeting, S.T. Picraux and W. J. Choyke, eds., MRS Symposia Proceedings, Vol. 7, North-Holland, 1982, pp. 433-440.

TABLE I.-ION BEAM TEXTURED HIGH

ABSORPTANCE METALS AND COM-

MERCIALLY AVAILABLE COAT-

INGS FLOWN ON LDEF

\begin{tabular}{|l|r|r|r|r|}
\hline \multicolumn{1}{|c|}{ Sample } & \multicolumn{2}{c|}{$\begin{array}{c}\text { Solar } \\
\text { absorptance }\end{array}$} & \multicolumn{2}{c|}{$\begin{array}{c}\text { Thermal } \\
\text { emittance, } \\
\text { 325 K }\end{array}$} \\
\cline { 2 - 5 } & 1982 & 1990 & 1982 & 1990 \\
\hline $\mathrm{Si}$ & 0.95 & 0.96 & 0.71 & 0.68 \\
$\mathrm{Ti}$ & .88 & .88 & .21 & .18 \\
$\mathrm{Cu}$ & .94 & .94 & .50 & .69 \\
Graphite & .96 & .96 & .78 & .77 \\
Inconel & .92 & .92 & .25 & .25 \\
Stainless steel & .91 & .93 & .26 & .28 \\
Black chrome & .90 & .90 & .18 & .18 \\
Nextal paint & .97 & .97 & .91 & .91 \\
\hline
\end{tabular}


TABLE II.-OPTICAL, CHEMICAL, AND PHYSICAL PROPERTIES

OF DLC FILMS GENERATED USING METHANE WITH SINGLE OR DUAL BEAM ION SOURCES

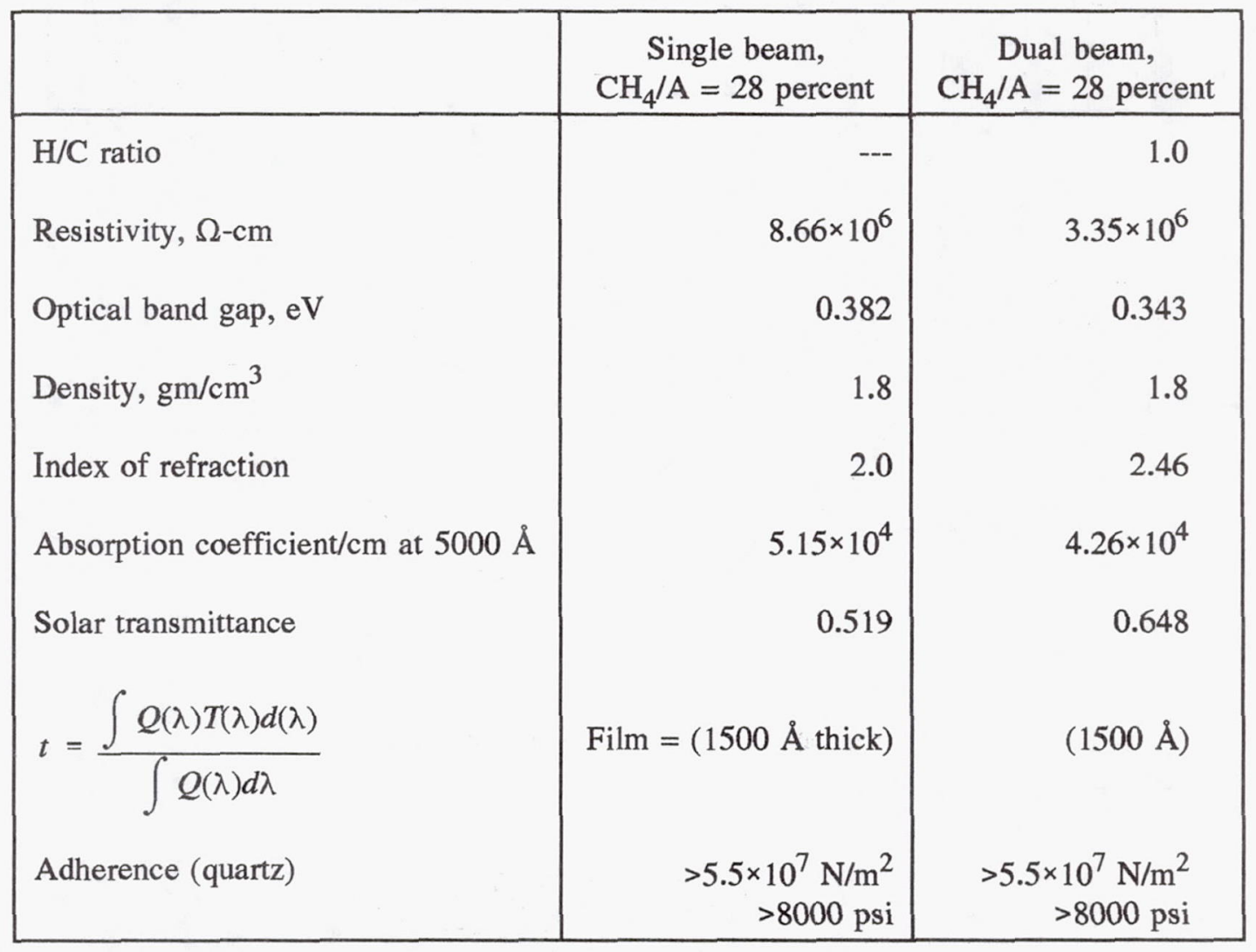

where: $Q(\lambda)=6000 \mathrm{~K}$ blackbody.

$T(\lambda)=$ transmittance at a given wavelength . 


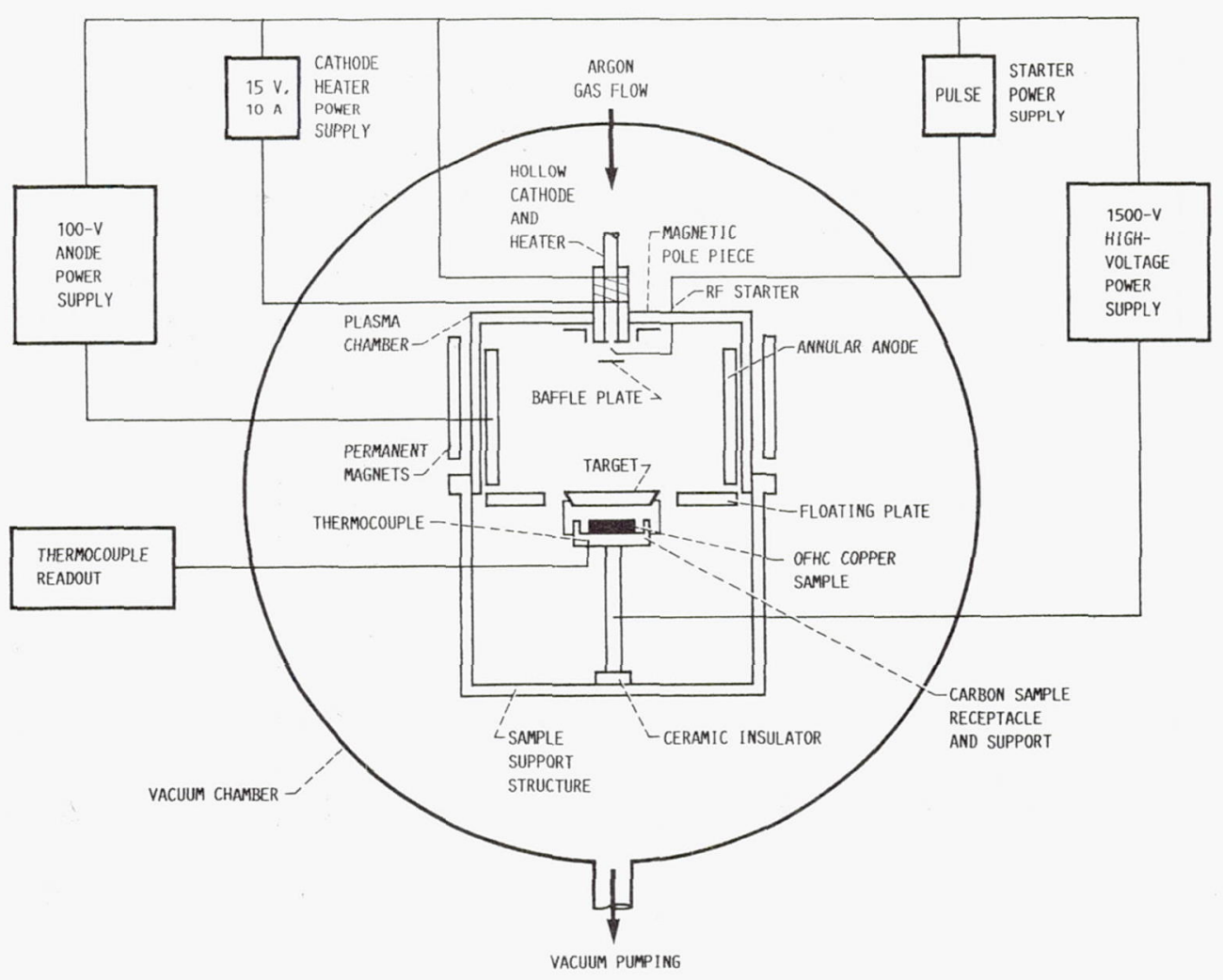

(a) Schematic of ion-texturing apparatus.

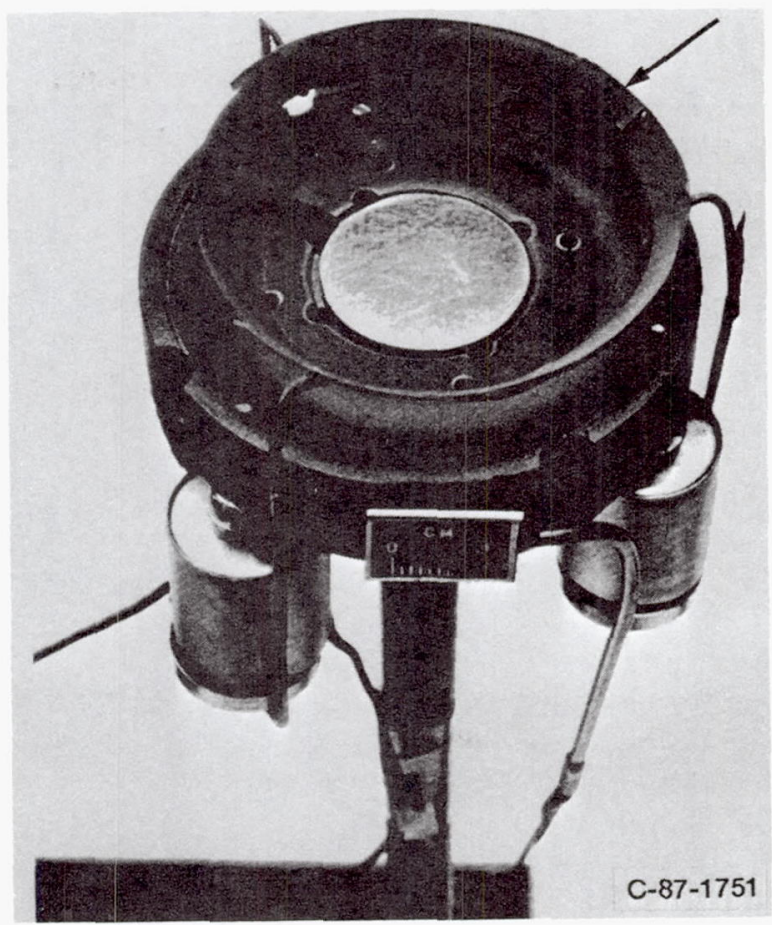

(b) Photo of sample in holder. The arrow points to the tantalum seed.

Figure 1.-Discharge chamber ion beam texturing apparatus. 


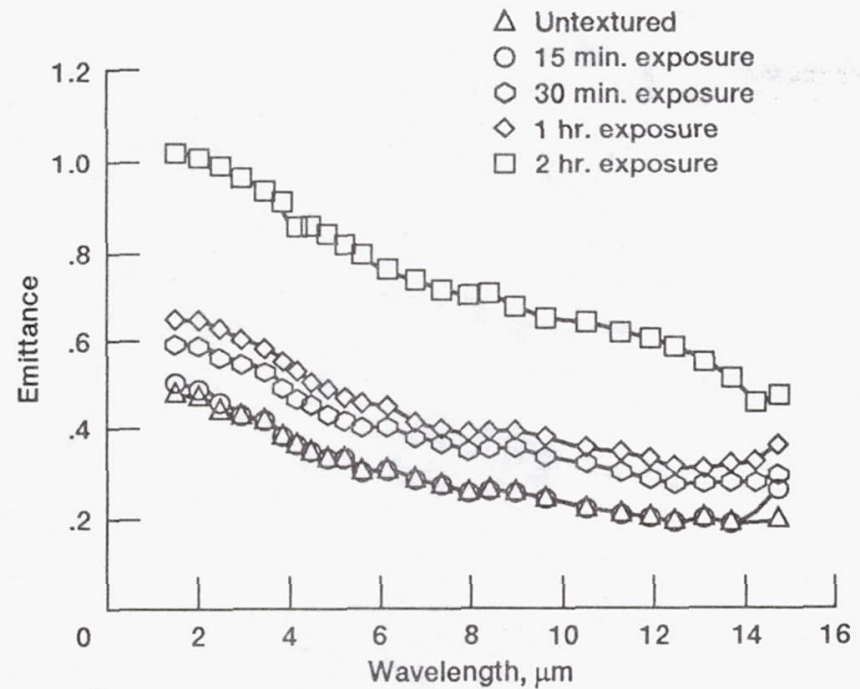

Figure 2.- Spectral emittance as a function of wavelength for Titanium discharge chamber textured for various lengths of time.

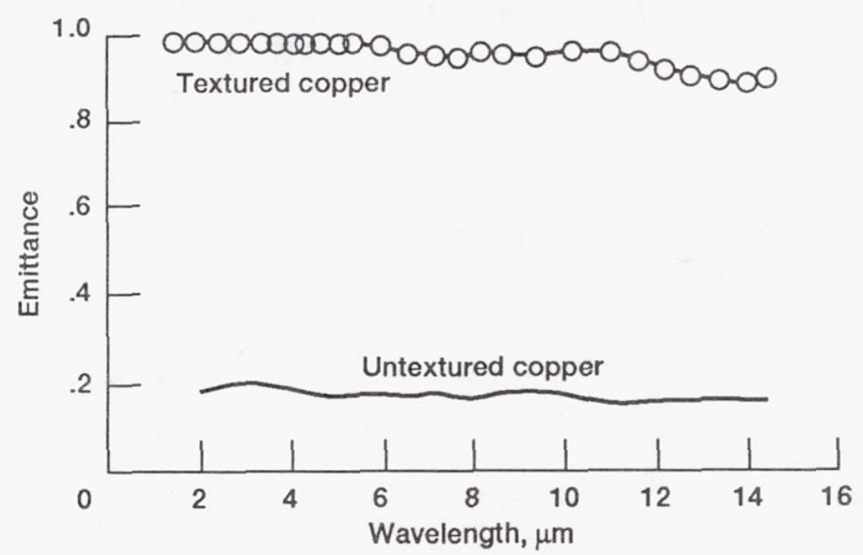

Figure 3.- Spectral emittance as a function of wavelength for Copper discharge chamber textured for 2 hours.

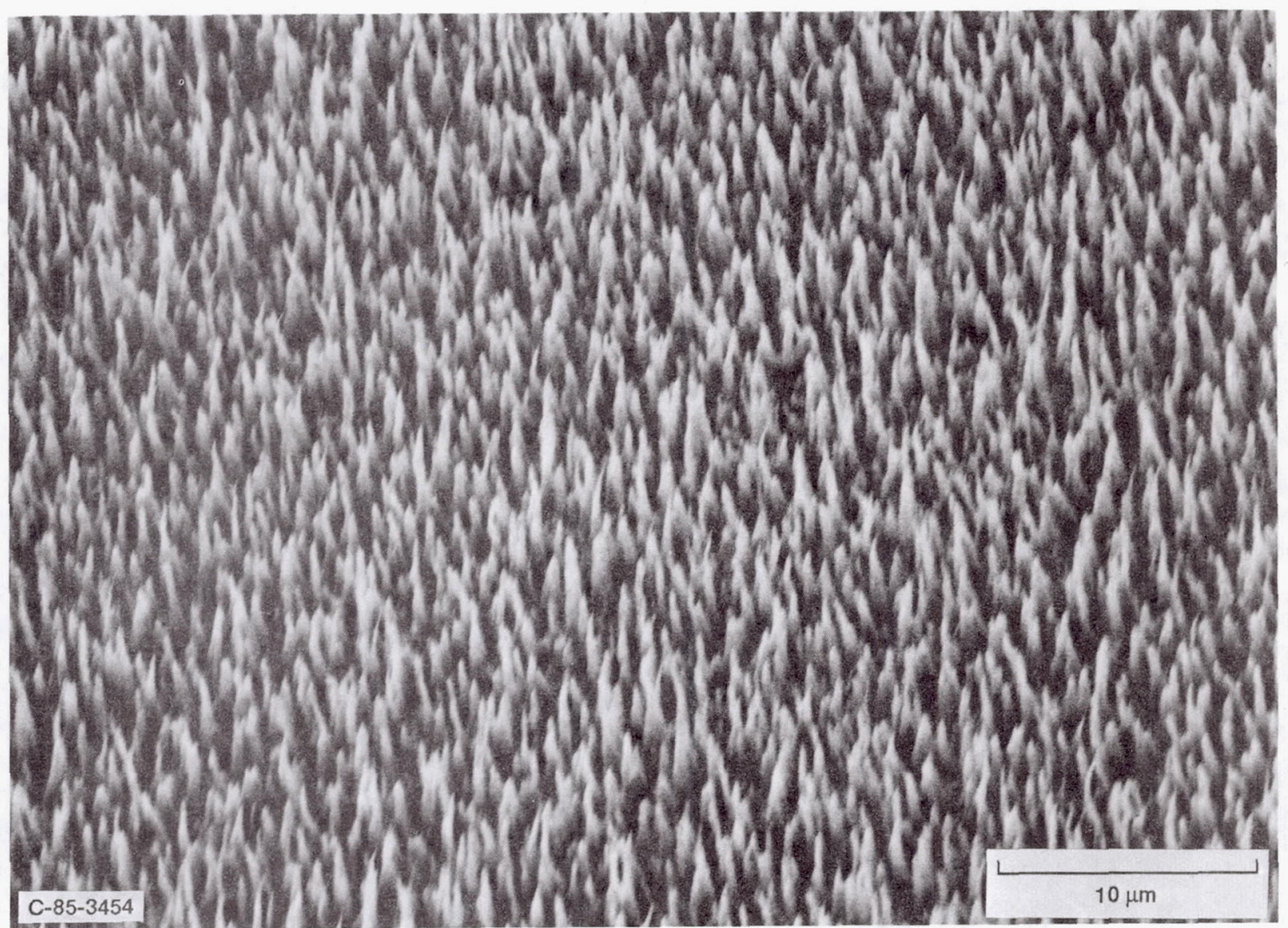

Figure 4.-Scanning-electron-microscope photomicrograph of textured carbon surface on OFHC copper substrate. Angle with surface, $30^{\circ}$. Processing time, 3 hours at $5 \mathrm{ma} / \mathrm{cm}^{2}$. 


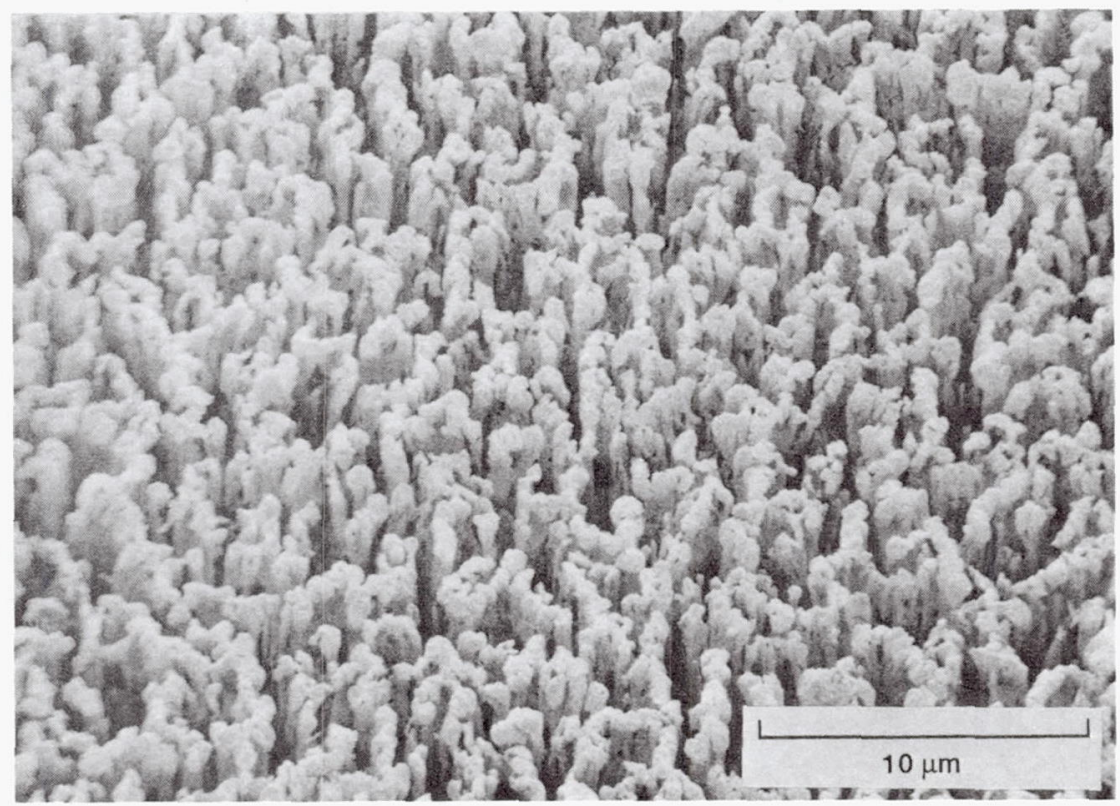

Figure 5.-Scanning-electron-microscope photomicrograph of textured OFHC copper processed with tantalum masking. Angle with surface, $30^{\circ} \mathrm{C}$. Processing time, 3 hours at $5 \mathrm{ma} / \mathrm{cm}^{2}$.

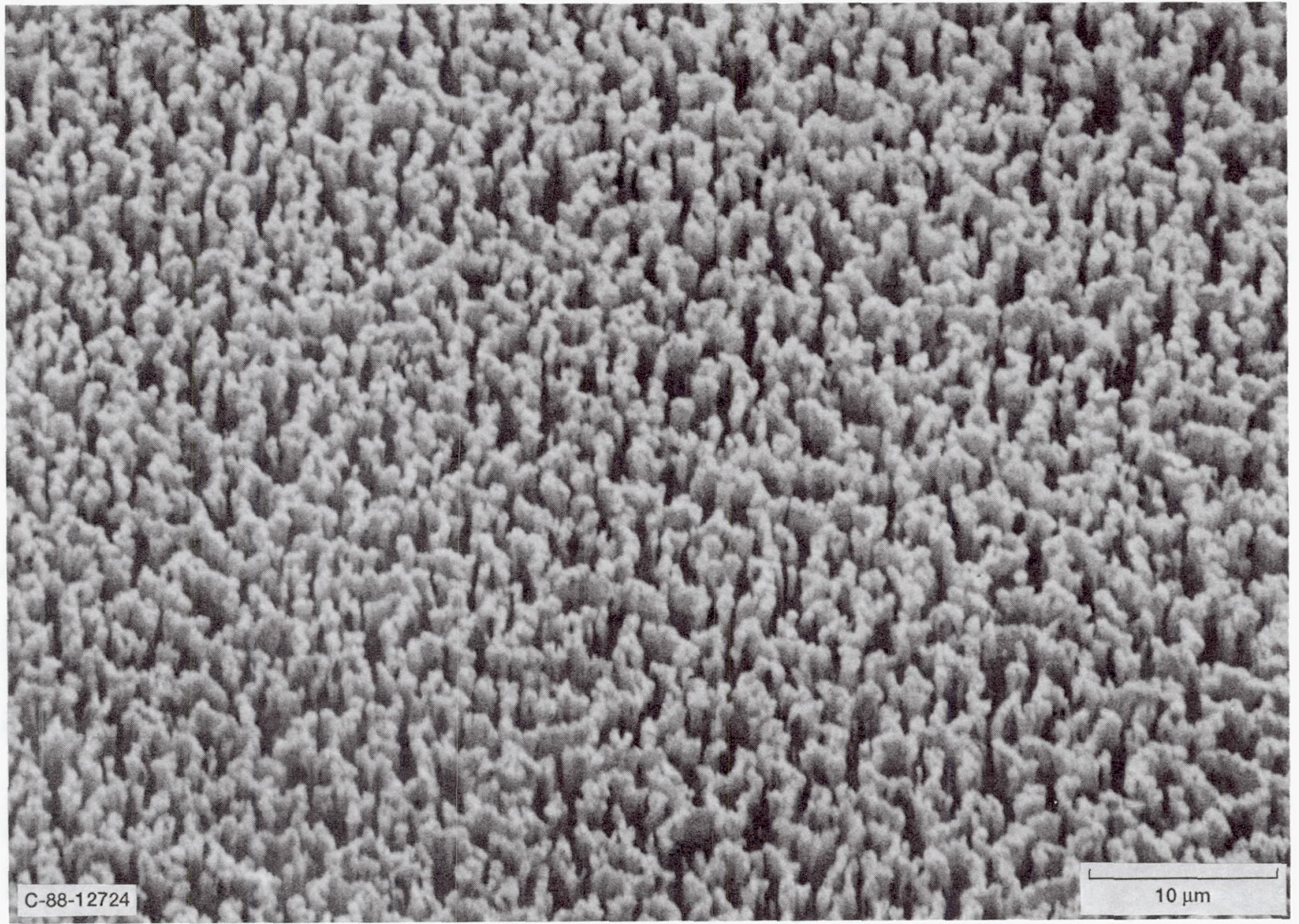

Figure 6.-Scanning-electron-microscope photomicrograph of textured OFHC copper processed with molybdenum masking. Angle with surface, $30^{\circ} \mathrm{C}$. Processing time, 2 hours at $5 \mathrm{ma} / \mathrm{cm}^{2}$. 

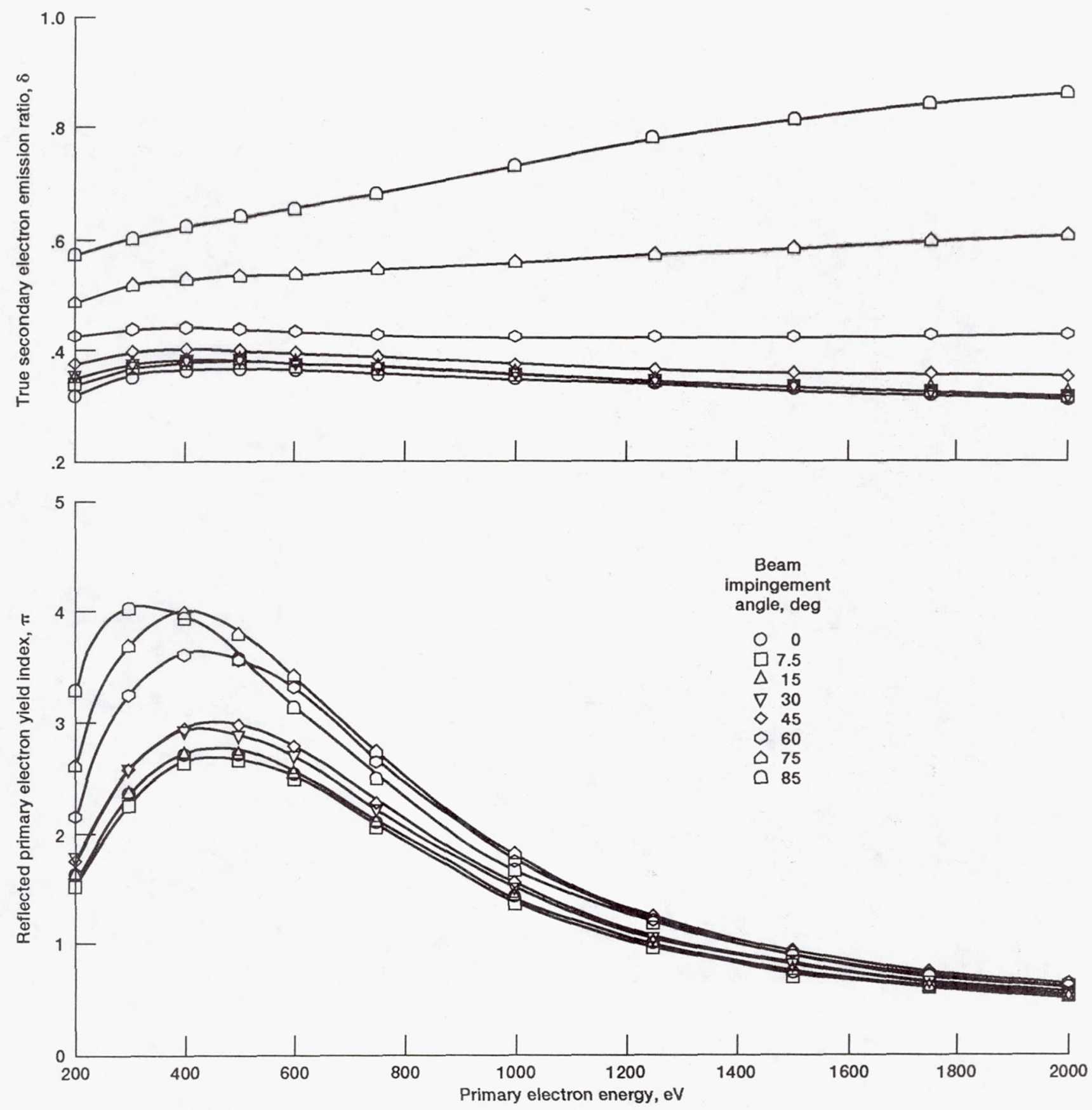

Figure 7.-Secondary electron emission characteristics of textured carbon on OFHC copper substrate and textured OFHC copper surfaces at right angle beam impingement as function of primary electron beam energy. 


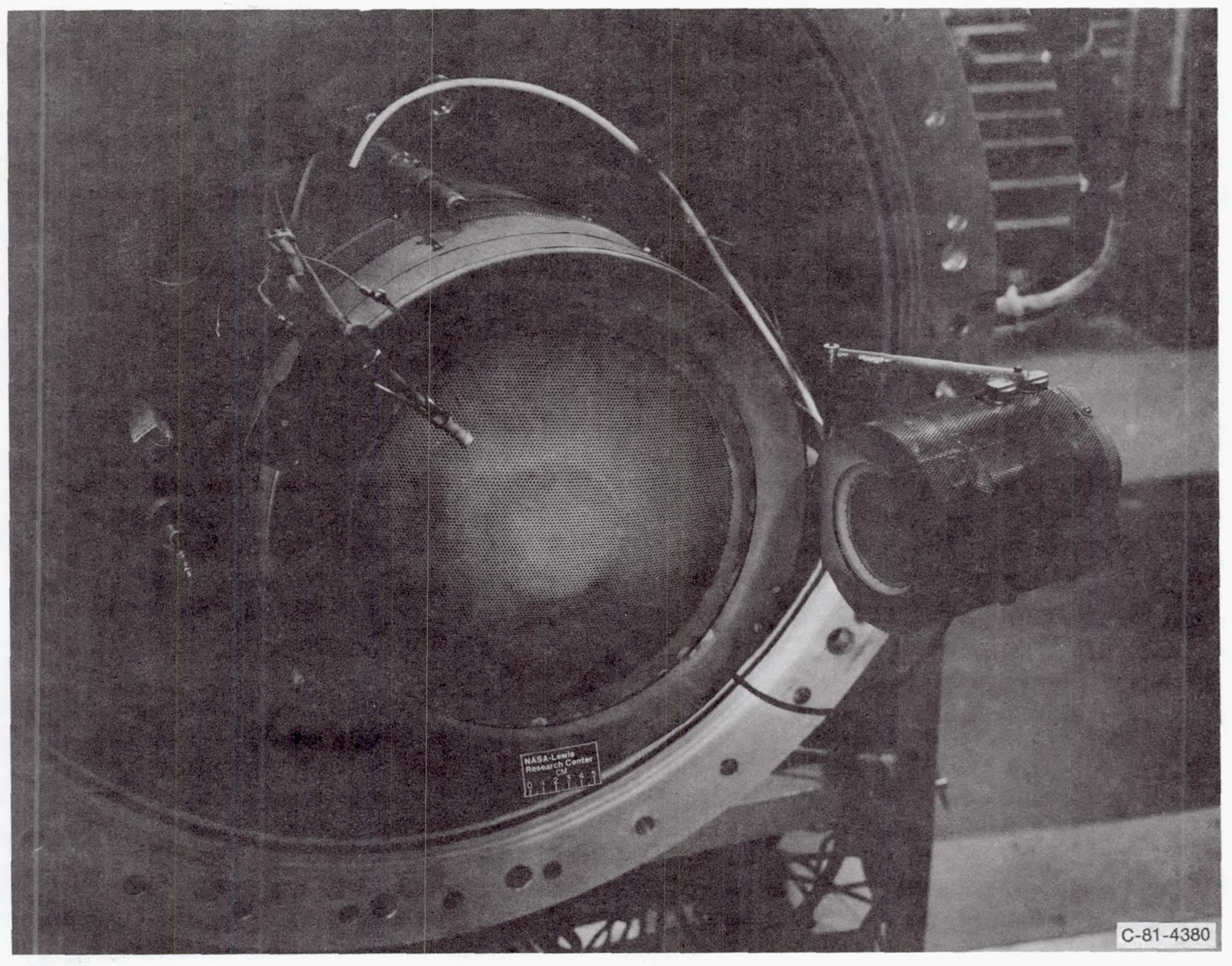

Figure 8.-The dual ion source configuration. 


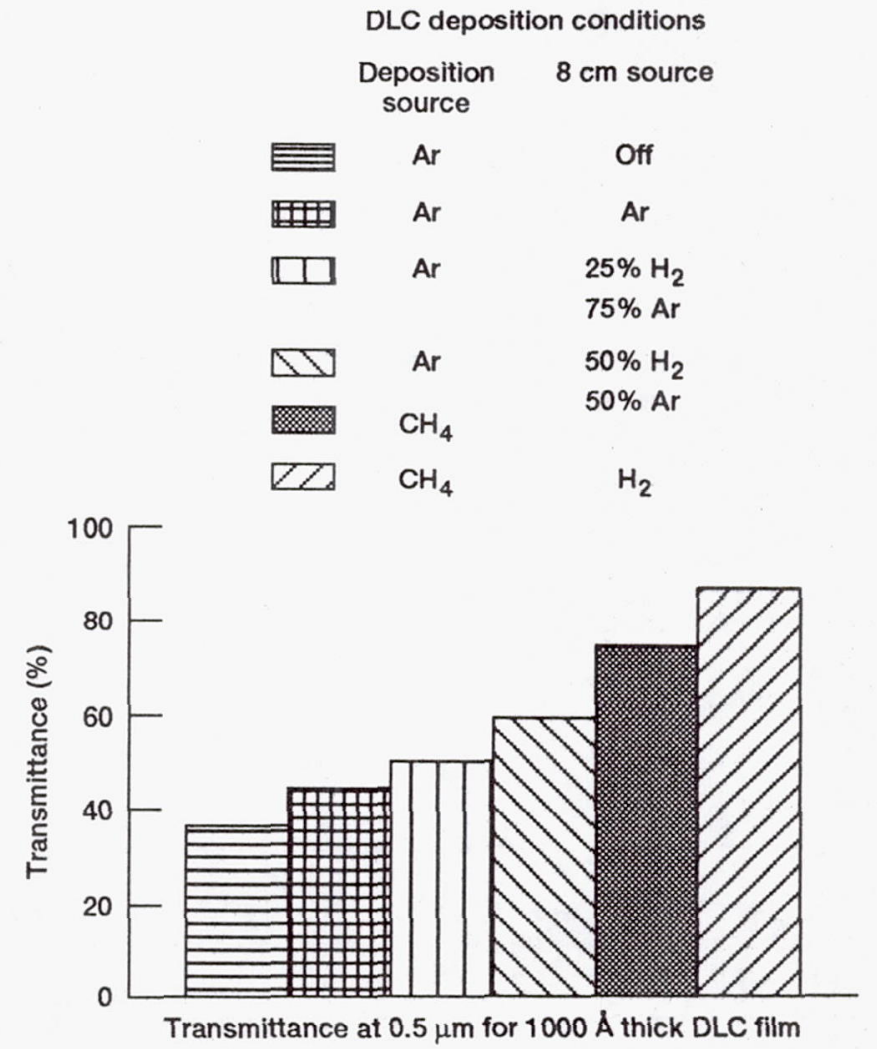

Figure 9.-Transmittance of DLC coatings deposited with various dual beam configurations.

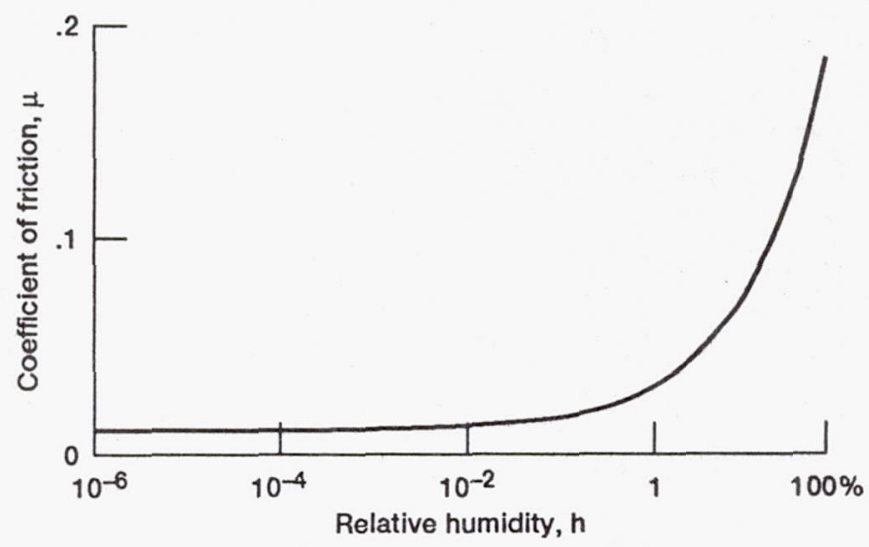

Figure 10.-The coefficient of friction, $\mu$, for DLC film sliding on steel, as a function of the relative humidity $h$. Up to about one percent humidity the coefficient of friction is very small; there is a marked increase when the humidity becomes greater. 
Public reporting burden for this collection of information is estimated to average 1 hour per response, including the time for reviewing instructions, searching existing data sources, gathering and maintaining the data needed, and completing and reviewing the collection of information. Send comments regarding this burden estimate or any other aspect of this collection of information, including suggestions for reducing this burden, to Washington Headquarters Services, Directorate for information Operations and Reports, 1215 Jefferson Davis Highway, Suite 1204, Arlington, VA 22202-4302, and to the Office of Management and Budget, Paperwork Reduction Project (0704-0188), Washington, DC 20503.

\begin{tabular}{|c|c|c|}
\hline 1. AGENCY USE ONLY (Leave blank) & $\begin{array}{r}\text { 2. REPORT DATE } \\
1992\end{array}$ & $\begin{array}{l}\text { 3. REPORT TYPE AND DATES COVERED } \\
\text { Technical Memorandum }\end{array}$ \\
\hline
\end{tabular}

4. TITLE AND SUBTITLE

Ion Beam Treatment of Potential Space Materials at the

NASA Lewis Research Center

6. AUTHOR(S)

Michael Kussmaul, Michael J. Mirtich, and Arthur Curren

7. PERFORMING ORGANIZATION NAME(S) AND ADDRESS(ES)

National Aeronautics and Space Administration

Lewis Research Center

Cleveland, Ohio 44135 - 3191

9. SPONSORING/MONITORING AGENCY NAMES(S) AND ADDRESS(ES)

National Aeronautics and Space Administration

Washington, D.C. 20546-0001

\section{FUNDING NUMBERS}

WU-506-41-41

8. PERFORMING ORGANIZATION REPORT NUMBER

E-6794

10. SPONSORING/MONITORING AGENCY REPORT NUMBER

NASA TM - 105398

\section{SUPPLEMENTARY NOTES}

Prepared for the Surface Modification of Metals by Ion Beams sponsored by the Naval Research Laboratory, Washington, D.C., July 15-19, 1991. Michael Kussmaul, Sverdrup Technology, Inc., Lewis Research Center Group, 2001 Aerospace Parkway, Brook Park, Ohio 44142; Michael J. Mirtich and Arthur Curren, NASA Lewis Research Center. Responsible person, Michael Kussmaul, (216) 433-8036.

12a. DISTRIBUTION/AVAILABILITY STATEMENT

12b. DISTRIBUTION CODE

Unclassified - Unlimited

Subject Category 23

\section{ABSTRACT (Maximum 200 words)}

Ion source systems, in different configurations, have been used to generate unique surface morphologies for several NASA space applications. The discharge chamber of a $30 \mathrm{~cm}$ ion source was successfully used to texture potential space radiator materials for the purpose of obtaining values of thermal emittance greater than 0.85 at 700 and $900 \mathrm{~K}$. High absorptance surfaces were obtained using ion beam seed-texturing, for space radiator materials that were flown on the Long Duration Exposure Facility (LDEF) for 5.8 years in space. An ion source discharge chamber was also used to develop electrode surfaces with suppressed secondary electron emission characteristics for use in collectors in microwave amplifier traveling wave tubes. This was accomplished by sputtering textured carbon onto copper as well as texturing copper using tantalum and molybdenum as sacrificial texture-inducing seeding materials. In a third configuration, a dual ion beam system was used to generate high transmittance diamondlike carbon (DLC) films.

\section{SUBJECT TERMS}

Secondary emission; Sputtering; Spacecraft radiators; Microwave emission; Thin films; Carbon; Diamond

17. SECURITY CLASSIFICATION OF REPORT

Unclassified
18. SECURITY CLASSIFICATION OF THIS PAGE Unclassified
19. SECURITY CLASSIFICATION OF ABSTRACT Unclassified
15. NUMBER OF PAGES

16

16. PRICE CODE

$\mathrm{A} 03$ 

National Aeronautics and Space Administration

Lewis Research Center

Cleveland, Ohio 44135

Official Business

Penalty for Private Use $\$ 300$
FOURTH CLASS MAIL

\section{AODRESS CORRECTION REQUESTED}

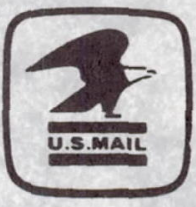

Postage and Fees Paid National Aeronautics and Space Administration NASA. 45 